\title{
Structural Characterization and Luminescence Behavior of a Silver(I) 1D Polymeric Chain Constructed via a Bridge with Unusual 4,5-Diazospirobifluorene and Perchlorate
}

\author{
Chih-Chieh Wang, ${ }^{*}, \dagger$ Cheng-Han Yang, ${ }^{\dagger}$ Shih-Min Tseng, ${ }^{\dagger}$ Sue-Yi Lin, ${ }^{\dagger} \mathrm{Ti}-\mathrm{Yu}$ Wu,${ }^{\dagger}$ Ming-Ren Fuh, ${ }^{\dagger}$ \\ Gene-Hsiang Lee, ${ }^{\ddagger}$ Ken-Tsung Wong, ${ }^{,} \S$ Ruei-Tang Chen, $\$$ Yi-Ming Cheng, $\$$ and Pi-Tai Chou ${ }^{\star, \$}$ \\ Department of Chemistry, Soochow University, Taipei, Taiwan 111, R.O.C., Instrumentation \\ Center, National Taiwan University, Taipei, Taiwan 106, R.O.C., and Department of Chemistry, \\ National Taiwan University, Taipei, Taiwan 106, R.O.C. \\ Received October 13, 2003
}

A new polymeric silver complex, $\left[\mathrm{Ag}_{2}\left(\mathrm{~L}_{2}\right)\left(\mathrm{ClO}_{4}\right)_{2}\right](\mathrm{L}=4,5$ diazospirobifluorene), has been synthesized and shown to exhibit interesting luminescence properties in a single crystal. Structural analysis reveals a one-dimensional chain, which contains a $\left[\mathrm{Ag}_{2}-\right.$ $\left.\left(\mathrm{L}_{2}\right)\right]^{2+}$ dimer bridged with $\mathrm{ClO}_{4}^{-}$. The $\mathrm{Ag} \cdots$ Ag distances are 2.776(1) and 4.575(1) $\AA$ incorporated by two $\mathrm{L}$ ligands and by a $\mathrm{ClO}_{4}^{-}$ bridge, respectively.

Polymeric silver complexes have recently received considerable attention owing to their fascinating photophysical and photochemical properties. ${ }^{1}$ The presence of structural diversity with different $\mathrm{Ag} \cdots \mathrm{Ag}$ interactions has proven to be one of the crucial factors contributing to such properties. ${ }^{2,3}$ Many silver complexes with either ligand-supported or ligand-unsupported $\mathrm{Ag} \cdots \mathrm{Ag}$ interactions have shown novel structural architectures and interesting luminescent properties. $^{4-9}$ Prototypical bridging nitrogen-based ligands like

* Author to whom correspondence should be addressed. E-mail: ccwang@ mail.scu.edu.tw.

$\dagger$ Soochow University.

Instrumentation Center, National Taiwan University.

$\S$ Department of Chemistry, National Taiwan University.

(1) (a) Henary, M.; Zink, J. I. Inorg. Chem. 1991, 30, 3111. (b) Sabin, F.; Ryu, C. K.; Ford, P. C.; Vogler, A. Inorg. Chem. 1992, 31, 1941. (c) Ford, P. C.; Vogler, A. Acc. Chem. Res. 1993, 26, 220. (d) Che, C. M.; Yip, H. K.; Yam, V. W. W.; Chueng, P. Y.; Lai, T. F.; Shieh, S. J.; Peng, S. M. J. Chem. Soc., Dalton Trans. 1992, 427.

(2) (a) Sun, D.; Cao, R.; Weng, J.; Hong, M.; Liang, Y. J. Chem. Soc., Dalton Trans. 2002, 291-292. (b) Su, W. P.; Hong, M. C.; Weng, J. B.; Cao, R.; Lu, S. F. Angew. Chem., Int. Ed. 2000, 39, 2911.

(3) Pyykkö, P. Chem. Rev. 1997, 97, 597 and references therein.

(4) Yam, V. W.-W.; Lo, K. K.-W.; Wang, C. R.; Cheung, K.-K. Inorg. Chem. 1996, 35, 5116.

(5) Che, C. M.; Tse, M. C.; Chan, M. C. W.; Cheung, K. K.; Phillips, D. L.; Leung, K. H. J. Am. Chem. Soc. 2000, 122, 2464.

(6) Sabin, F.; Ryu, C. K.; Ford, P. C.; Vogler, A. Inorg. Chem. 1992, 31, 1941.

(7) Seward, C.; Chan, J.; Song, D.; Wang, S. Inorg. Chem. 2003, 42, 1112.

(8) Be, X. H.; Liu, H.; Du, M.; Wong, K. M. C.; Yam, V. W. W. Inorg. Chem. 2001, 40, 4143 .

(9) (a) Fei, B. L.; Sun, W. Y.; Okamura, T. A.; Tang, W. X.; Ueyama, N. New J. Chem. 2001, 25, 210. (b) Fei, B. L.; Sun, W. Y.; Zhang, Y. A.; Yu, K. B.; Tang, W. X. Inorg. Chim. Acta 2000, 306, 107.

Scheme 1. Coordination Modes of Bis-Monodentate Nitrogen-Based Ligands

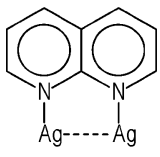

I

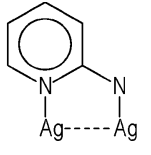

II<smiles>[R]N1C=NC=[Ge]1</smiles>

III

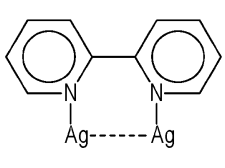

IV types I-III depicted in Scheme 1 have been widely used for the coordination with silver ion. The resulting fivemembered chelate ring complexes usually show rather short Ag $\cdots$ Ag distances of $<2.80 \AA .{ }^{10-12}$ However, no particularly short $\mathrm{Ag} \cdots \mathrm{Ag}$ distance has been reported with type IV ligands, forming a six-membered chelate ring (see Scheme 1). Herein, we report the synthesis, structural characterization, and luminescence behavior of a one-dimensional (1D), perchlorate-bridged linear-chain $\operatorname{Ag}(\mathrm{I})$ complex, $\left[\operatorname{Ag}_{2}\left(\mathbf{L}_{2}\right)\right.$ $\left.\left(\mathrm{ClO}_{4}\right)_{2}\right]\left(\mathrm{CH}_{3} \mathrm{CN}\right)(\mathbf{L}=4,5$-diazospirobifluorene), denoted as compound 1, in which the $\mathrm{Ag} \cdots \mathrm{Ag}$ distance is significantly short via the bridging nitrogen-based ligand ascribed to the type IV mode.

The N-based ligand, 4,5-diazospirobifluorene, used here was prepared by a modified literature procedure. ${ }^{13}$ The Grignard reagent of 2-iodobiphenyl in ether was added with cyclopenta[2,1- $\left.b ; 3,4-b^{\prime}\right]$ dipyridin-5-one in THF to furnish the adduct, which was subsequently cyclized by treatment with $\mathrm{H}_{2} \mathrm{SO}_{4}$ (2.5 equiv) in refluxing HOAc to afford the product in $76 \%$ yield.

A solution containing $\mathrm{AgClO}_{4}(0.18 \mathrm{mmol})$ and 4,5diazospirobifluorene $(0.18 \mathrm{mmol})$ in $\mathrm{CH}_{3} \mathrm{CN}(40 \mathrm{~mL})$ was stirred for $2 \mathrm{~h}$ at room temperature. The resulting colorless solution was filtered and concentrated to $5 \mathrm{~mL}$. Single plate crystals of compound $\mathbf{1}$ suitable for X-ray diffraction and

(10) Cotton, F. A.; Feng, X.-J.; Matusz, M.; Poli, R. J. Am. Chem. Soc. 1988, 110, 7077.

(11) Tsuda, T.; Ohba, S.; Takahashi, M.; Ito, M. Acta Crystallogr. C 1989, $45,887$.

(12) Radak, S.; Ni, Y.; Xu, G.; Shaffer, K. L.; Ren, T. Inorg. Chim. Acta 2001, 321, 200.

(13) Piotrowiak, P.; Kobetic, R.; Schatz, T. R.; Tapper, S. Bull. Pol. Acad. Sci. Chem. 1994, 42, 445.

Inorganic Chemistry, Vol. 43, No. 16, 20044781 


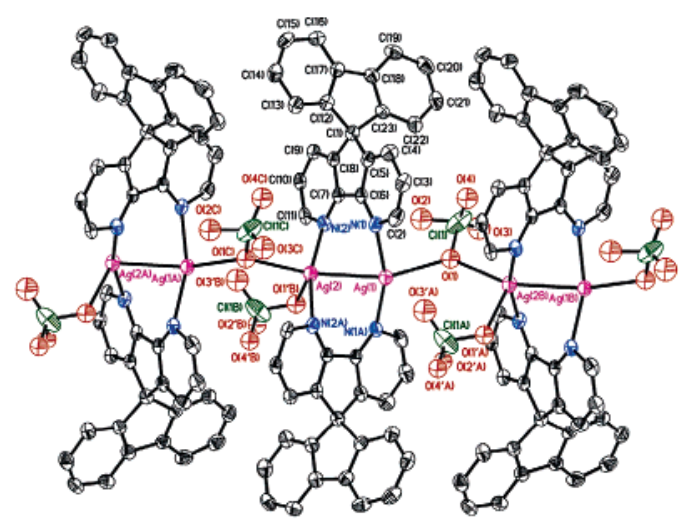

(a)

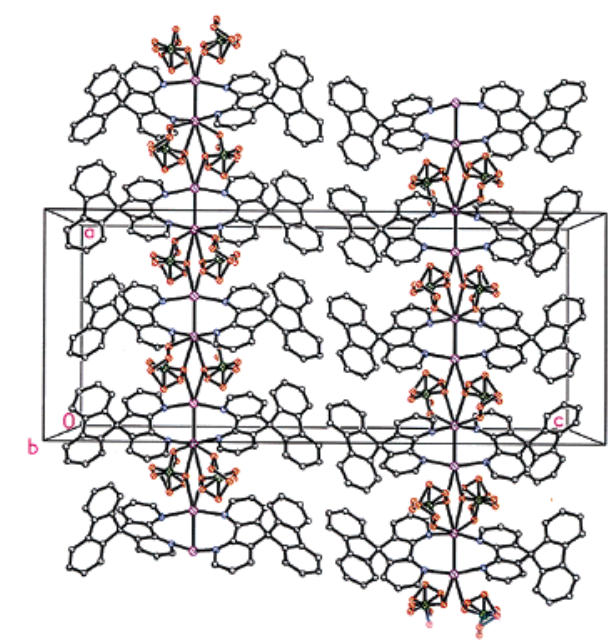

(b)

Figure 1. (a) ORTEP view of $\left[\mathrm{Ag}\left(4,5 \text {-diazosphirobifluorene) }\left(\mathrm{ClO}_{4}\right)\right]_{2} \cdot \mathrm{CH}_{3}\right.$ CN (1) with $30 \%$ thermal ellipsoid probability. (b) 1D linear chain via the bridge of the $\left[\mathrm{Ag}_{2}(\mathbf{L})_{2}\right]^{2+}$ dimeric unit with $\mathrm{ClO}_{4}{ }^{-}$along the $a$-axis.

luminescence studies were obtained in $74 \%$ yield by slow diffusion of diethyl ether into the filtrate for several days. Elemental analysis confirmed the formula of $\mathbf{1} .^{14}$

As revealed by the $\mathrm{X}$-ray structural analysis (see Figure 1a), ${ }^{15}$ the single crystal of compound $\mathbf{1}$ possesses a $1 \mathrm{D}$ chain. The asymmetric unit contains two crystallographically independent silver(I) ions $(\operatorname{Ag}(1)$ and $\operatorname{Ag}(2))$ located at a 2 -fold axis. As expected for pyridine-type ligand coordinated $\mathrm{Ag}(\mathrm{I})$ complexes, ${ }^{16}$ 4,5-diazospirobifluorene acts as a bridging ligand bonded to two $\mathrm{Ag}$ atoms through its two nitrogen atoms with $\mathrm{Ag}-\mathrm{N}$ bond distances of $\mathrm{Ag}(1)-\mathrm{N}(1), 2.251(5)$ $\AA$, and $\mathrm{Ag}(2)-\mathrm{N}(2), 2.215(5) \AA$, and a $\mathrm{N}(1)-\mathrm{Ag}(1)-\mathrm{Ag}$ (2) $-\mathrm{N}(2)$ dihedral angle of $61.59(2)^{\circ}$. Two Ag atoms are incorporated by two 4,5-diazospirobifluorene ligands to form a $\left[\operatorname{Ag}_{2}\left(\mathbf{L}_{2}\right)\right]^{2+}$ dimer. The $\mathrm{Ag}-\mathrm{Ag}$ distance of $2.776(1) \AA$ is obviously shorter than that of e.g. $2.890(2) \AA$ in $\left[\left\{\mathrm{Ru}(\text { pap })_{2^{-}}\right.\right.$ $\left.\left.(\mathrm{Biim})_{2}\right\} \mathrm{Ag}_{2}\right]\left(\mathrm{ClO}_{4}\right)_{2} \cdot \mathrm{H}_{2} \mathrm{O}^{17}$ possessing the type IV coordination mode. However, it falls in the same range as the analogues of silver complexes with type I-III nitrogen-based ligands depicted in Scheme $1 .^{10-12}$ The result demonstrates for the first time an unusually short $\mathrm{Ag}-\mathrm{Ag}$ distance adopting a six-membered chelating ring configuration of a type IV coordination mode. It is also interesting to note that adjacent $\left[\mathrm{Ag}_{2}(\mathbf{L})_{2}\right]^{2+}$ dimers are linked through a bridge of the $\mathrm{ClO}_{4}^{-}$ ion with $\mathrm{Ag}-\mathrm{O}_{\text {perchlorate }}$ bond distances of $\mathrm{Ag}(1)-\mathrm{O}(1) 2.587$ -

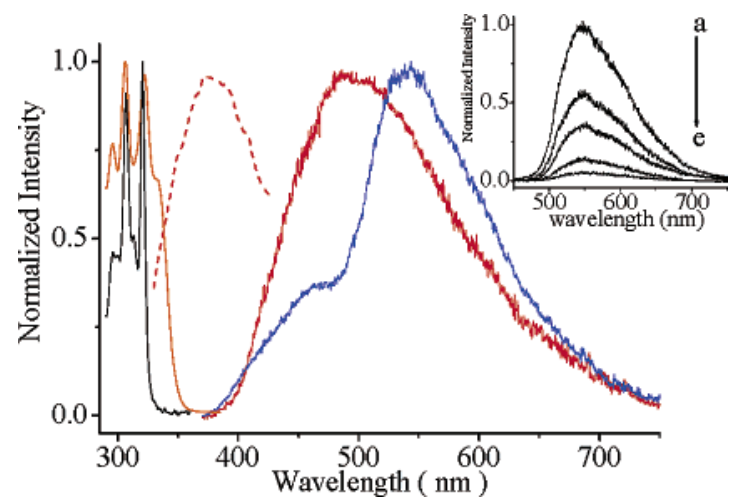

Figure 2. Absorption of $\mathbf{L}$ (black -) and $\mathbf{1}$ (orange -) at $298 \mathrm{~K}$ in THF; emission of $\mathbf{1}$ in a single crystal at 298 (red - ) and $77 \mathrm{~K}$ (blue -); (red - - ) excitation spectrum of solid 1 at $298 \mathrm{~K}$. Inset: spectral temporal evolution of solid 1 at $77 \mathrm{~K}$ acquired at a delay time of (a) 1, (b) 2, (c) 5 , (d) 15 , and (e) $30 \mu \mathrm{s}$.

(9) $\AA$ and $\mathrm{Ag}(2)-\mathrm{O}(1) 2.597(9) \AA$ as well as the $\mathrm{Ag} \cdots \mathrm{Ag}$ separation of 4.575(1) $\AA$, constructing a polymeric linear chain (Figure 1b). Furthermore, the adjacent chains are selforganized via the weak $\pi-\pi$ stacking interaction of benzene rings in $\mathbf{L}$ with a separation distance of $3.930 \AA$ between two centroid rings.

In tetrahydrofuran (THF), the dominant vibronic absorption peak in compound $\mathbf{1}$ at 320, 310 (shoulder), and 305 $\mathrm{nm}$ can be ascribed to the ligand-centered (LC) $\pi-\pi^{*}$ transitions $\left(\epsilon_{320} \sim 2.2 \times 10^{4} \mathrm{M}^{-1} \mathrm{~cm}^{-1}\right)$. These spectral assignments were made on the basis of their spectral similarities with those of free ligand $\mathbf{L}$ (see Figure 2). Comparing ligand $\mathbf{L}$, the appearance of a shoulder at $\sim 330$ $\mathrm{nm}$ accompanied by a bathochromic shift of the spectral onset toward $360 \mathrm{~nm}$ in compound $\mathbf{1}$ indicates that upon complexation the lowest energy gap might be manifested by the $\pi-\pi$ interaction of adjacent ligands. Interestingly, unlike the moderately strong fluorescence observed for ligand $\mathbf{L}$ in THF $\left(\lambda_{\max } \sim 350 \mathrm{~nm}, \Phi_{\mathrm{f}} \sim 7 \times 10^{-3}\right)$, compound 1 is intrinsically nonluminescent throughout $350-800 \mathrm{~nm}$ in organic solvents such as THF, $\mathrm{CH}_{2} \mathrm{Cl}_{2}$, and $\mathrm{CH}_{3} \mathrm{CN}$ at $298 \mathrm{~K}$. In contrast, the single crystal form of compound $\mathbf{1}$ revealed a prominent emission maximized at $\sim 490 \mathrm{~nm}$, of which the decay was well fitted by a single-exponential component with $\tau_{\mathrm{f}} \sim 2.5$

(14) Anal. Calcd for $\mathrm{C}_{48} \mathrm{H}_{31} \mathrm{Ag}_{2} \mathrm{Cl}_{2} \mathrm{~N}_{5} \mathrm{O}_{8}$ : C 52.77, N 6.41, H 2.86. Found: C 53.12, N 6.68, H 2.83.

(15) Single-crystal structure analysis was performed on a Nonius Kappa diffractometer with a CCD detector with Mo radiation $(\lambda=0.71073$ $\AA$ ). Crystal data for 1: $\mathrm{C}_{48} \mathrm{H}_{31} \mathrm{Ag}_{2} \mathrm{Cl}_{2} \mathrm{~N}_{5} \mathrm{O}_{8}, M_{\mathrm{r}}=1092.42$, orthorhombic, Ibca, $a=14.7025(2) \AA, b=16.2288(2) \AA, c=35.6620(5)$ $\AA, V=8509.1(2) \AA^{3}, D_{\mathrm{c}}=1.705 \mathrm{~g} \cdot \mathrm{cm}^{-3}, T=150(2) \mathrm{K}, Z=8$, $\mu(\mathrm{Mo} \mathrm{K} \alpha)=1.110 \mathrm{~mm}^{-1}$. A total of 29177 reflections were collected with a final resolution of $0.70 \AA$. SADABS absorption correction $\left(T_{\min }\right.$ 0.707 and $\left.T_{\max } 0.987\right), 4896$ unique reflections $\left(2 \theta<55^{\circ}, R_{\text {int }}=\right.$ 0.0734 ) were used in the refinement. Full-matrix least-squares refinement on $F^{2}$ converged to $R_{F}$ and $R_{\mathrm{w}}\left(F^{2}\right)$ values of 0.0714 and 0.1851 for 293 parameters and 3521 unique reflections with $I \geq 2 \sigma(I)$ and 0.1041 and 0.2118 for all 4896 reflections. The CCDC reference number is 212568 for $\mathbf{1}$

(16) (a) Yaghi, O. M.; Li, H. J. Am. Chem. Soc. 1996, 118, 295. (b) Withersby, M. A.; Blake, A. J.; Champness, N. R.; Hubberstey, P.; Li, W.-S.; Schröder, M. Angew. Chem., Int. Ed. Engl. 1997, 36, 2327. (c) Carlucci, L.; Ciani, G.; Macchi, P.; Proserpio, D. M. Chem. Commun. 1998, 1837. (d) Tong, M.-L.; Chen, X.-M.; Ye, B.-H.; Ng, S. W. Inorg. Chem. 1998, 37, 5278. (e) Tong, M.-L.; Chen, X.-M.; $\mathrm{Ng}, \mathrm{S}$. W. Inorg. Chem. Commun. 2000, 3, 436.

(17) Majumdar, P.; Kamar, K. K.; Castineiras, A.; Goswami, S. Chem. Commun. 2001, 1291. 
ns. ${ }^{18}$ The results, in combination with the mirror image between excitation and emission spectra (see Figure 2), lead us to conclude the $490 \mathrm{~nm}$ emission in a single crystal to be of the fluorescence characteristic. At $77 \mathrm{~K}$ dual emission appeared, consisting of a $\sim 480 \mathrm{~nm}$ shoulder and a $550 \mathrm{~nm}$ band. The $\sim 480 \mathrm{~nm}$ band with a $\tau_{\mathrm{f}}$ value measured to be $4.3 \mathrm{~ns}$ is reasonably ascribed to the fluorescence that is slightly blue shifted from the room temperature $490 \mathrm{~nm}$ band. Upon acquiring the emission at a delay time of $>1 \mu \mathrm{s},{ }^{18}$ the $480 \mathrm{~nm}$ band disappears, and the remaining $550 \mathrm{~nm}$ band reveals phosphorescence characteristics with a slow decay time of $\tau_{\mathrm{p}} \sim 6 \mu$ s (see the inset of Figure 2).

Comparing the absorption spectrum of $\mathbf{1}$ in the solution phase, the excitation spectrum in a single crystal is red shifted by $\sim 3600 \mathrm{~cm}^{-1}$. While the 4,5 -diazospirobifluorene binding $\mathrm{Ag}$ remains intact in solution, as indicated by the similar but red shifted absorption profile with respect to that of the free 4,5-diazospirobifluorene in THF, the drastically different photophysical behavior is believed to be due to the breakdown of the 1D chain in solution. This viewpoint can be further supported by the electrospray mass spectrum of compound $\mathbf{1}$ dissolved in acetonitrile solution, in which three peaks appeared at $734.4,851.6$, and $1061.6(\mathrm{~m} / \mathrm{z})$ with a relative abundance ratio of $\sim 100: 1: 10$, corresponding to $[\mathrm{Ag}$ $\left.\left(\mathbf{L}_{2}\right)\right]^{+},\left[\operatorname{Ag}_{2}\left(\mathbf{L}_{2}\right)\right]^{+}$, and $\left[\operatorname{Ag}\left(\mathbf{L}_{3}\right)\right]^{+}$, respectively. This result suggests that the polymeric $1 \mathrm{D}$ chain of compound $\mathbf{1}$ in a single crystal is plausibly not maintained in solution. ${ }^{19}$

The environmental perturbation, e.g. the crystal packing effect in the solid state, has been noticed in several $\mathrm{Au}(\mathrm{I})$ and $\operatorname{Ag}(\mathrm{I})$ types of $\mathrm{d}^{10}$ metal complexes, ${ }^{20,21}$ and the $\mathrm{Ag}(\mathrm{I})$ $4 \mathrm{~d} \sigma^{*} \rightarrow 5 \mathrm{p}$ transition perturbed by the $\mathrm{Ag}(\mathrm{I})-\mathrm{Ag}(\mathrm{I})$ interaction has been systematically approached. Depending on the changes in metal/ligand coordination as well as the $\mathrm{Ag}(\mathrm{I})-$ $\mathrm{Ag}(\mathrm{I})$ distance, the origin of the emission can be drastically altered. ${ }^{5,21}$ In the case of compound $\mathbf{1}$, due to its different fluorescence spectral feature from free ligand $\mathbf{L}\left(\lambda_{\text {flu }} \sim 375\right.$ $\mathrm{nm}$ in solid crystal), the possible origin of the $\sim 490 \mathrm{~nm}$ fluorescence in a single crystal involving $\mathrm{Ag}(\mathrm{I})$ such as the $\mathrm{Ag} \cdots \mathrm{Ag}$ transition has been carefully examined. In one approach, since the $\mathrm{Ag} \cdots \mathrm{Ag}$ vector coincides with the $a$-axis, a polarized emission study has been carried out by carefully aligning a sheetlike crystal mounted on the capillary so that the $a$-axis of the crystal is perpendicular to the laboratory

(18) Absorption and emission spectra were recorded by a Hitachi (U-3310) spectrophotometer and an Edinburgh (FS920) fluorimeter, respectively. A configuration of front-face excitation was used to measure the emission of the single crystal. Lifetime studies were performed by an Edinburgh FL 900 photon-counting system. For phosphorescence measurements, a Nd:YAG (355 nm, $8 \mathrm{~ns}$, Continuum Surlite II) pumped optical parametric oscillator was used as an excitation source. The resulting luminescence was then detected by an intensified charge coupled detector.

(19) In addition to compound 1, recrystallization from $\mathrm{CH}_{3} \mathrm{CN}$ gives rise to minor products possibly in the form of $\mathrm{Ag}_{2} \mathbf{L}_{n}$. Detailed structural characterization is in progress and will be elaborated in a full paper.

(20) Irwin, M. J.; Vittal, J. J.; Puddephatt, R. J. Organometallics 1997, 16, 3541.

(21) Ren, T.; Lin, C.; Amalberti, P.; Macikenas, D.; Protasiewicz, J. D.; Baum, J. C.; Gibson, T. L. Inorg. Chem. Commun. 1998, 1, 23.

(22) Lee, C.; Yang, W.; Parr, R. G. Phys. Rev. B 1988, 37, 785.

(23) Bauernschmitt, R.; Ahlrichs, R.; Hennrich, F. H.; Kappes, M. M. J. Am. Chem. Soc. 1998, 120, 5052. frame. In this study, the output of the excitation laser (third harmonic $355 \mathrm{~nm}, \mathrm{Nd}$ :YAG laser) was coupled with a halfwave plate and a Glan-Thompson linear polarizer to finetune the polarization without changes of the laser intensity. The results revealed that the $490 \mathrm{~nm}$ fluorescence intensity, within experimental error, was independent of the polarization vector of the excitation beam, ${ }^{\dagger}$ eliminating the origin of the $490 \mathrm{~nm}$ emission mainly from the linear $\mathrm{Ag} \cdots \mathrm{Ag}$ interaction. In another approach, theoretical computation has been performed, in which compound $\mathbf{1}$ was truncated into $\left[\mathrm{Ag}(\mathbf{L})_{2}\left(\mathrm{ClO}_{4}\right)_{2}\right](\mathbf{L}=4,5$-diazospirobifluorene $)$ to avoid the complexity. The ground state geometry was adapted from the truncated X-ray data. On the basis of this geometry, timedependent DFT (TDDFT) calculation using the B3LYP functional was performed. ${ }^{22,23 \dagger}$ The results indicate that the lowest singlet excitation is dominated by the combination of $\mathrm{HOMO} \rightarrow$ LUMO and HOMO $-1 \rightarrow$ LUMO transitions, in which both HOMO - 1 and HOMO are composed of d orbitals of $\operatorname{Ag}(\mathrm{I})$ and lone pair orbitals of the perchlorate bridge, while LUMO mainly consists of $\pi$ orbitals of ligand (4,5-diazospirobifluorene). As a result, the origin of $490 \mathrm{~nm}$ fluorescence is ascribed to a metal to ligand charge transfer transition ( $\left.{ }^{1} \mathrm{MLCT}\right)$ mixed, in part, with the $\pi^{*}(4,5-$ diazospirobifluorene) $\rightarrow \mathrm{n}$ (perchlorate bridge) transition. The $\pi$ stacking interaction between two centroid rings in the adjacent chains (vide supra) may play an important role to account for the $490 \mathrm{~nm}$ fluorescence in the single crystal of 1, which is otherwise absent in the free ligand. Accordingly, it is reasonable to assign the origin of $550 \mathrm{~nm}$ phosphorescence to possess a ${ }^{3}$ MLCT character. These assignments imply that both ${ }^{1}$ MLCT and ${ }^{3}$ MLCT are affected by the $\pi$ stacking interaction. Nevertheless, one cannot rule out the possibility that the state mixing may take place in the lowerlying triplet states between e.g. ${ }^{3} \pi \pi$ and ${ }^{3}$ MLCT manifolds, as supported by the similarity in spectral properties between the phosphorescence of compound $\mathbf{1}$ and that of free ligand $\mathbf{L}$ measured in a $77 \mathrm{~K}$ crystal solid $\left(\lambda_{\text {phos }} \sim 540 \mathrm{~nm}, \tau_{\text {phos }} \sim\right.$ 6. $2 \mu \mathrm{s}$ ). At this stage, a definitive assignment unfortunately is not possible without more sophisticated theoretical approaches to gain detailed insights into the energy correlation among various electronic states for nontruncated compound 1.

In summary, a new polymeric silver complex 1 incorporating 4,5-diazospirobifluorene as the ligand has been synthesized. The proximal $\mathrm{Ag}(\mathrm{I})-\mathrm{O}_{\text {pechhlorate }}$ interactions forming a 1D chain, in combination with the strong sixmembered-ring complexation in $\left[\mathrm{Ag}_{2}(\mathbf{L})_{2}\left(\mathrm{ClO}_{4}\right)_{2}\right]$, are believed to play key roles in observing the intriguing luminescent properties in a single crystal. From the application viewpoint, an ideal analogue of $\mathbf{1}$ for devices may exhibit optimum redox potential as well as strong, tunable emission. To achieve this goal, focus on $\left[\mathrm{Ag}_{2}\left(\mathbf{L}_{2}\right)\left(\mathrm{ClO}_{4}\right)_{2}\right]$ systems in which 4,5-diazospirobifluorene can be fine-tuned by adding various substituents is currently in progress.

Supporting Information Available: X-ray crystallographic file (CIF), theoretical approach, and polarized fluorescence. This material is available free of charge via the Internet at http://pubs.acs.org. IC0351794 